Jean-Christophe M. Richard John J. Marini

\section{Transpulmonary pressure as a surrogate of plateau pressure for lung protective strategy: not perfect but more physiologic}

Received: 11 December 2011

Accepted: 9 January 2012

Published online: 10 February 2012

(C) Copyright jointly held by Springer and ESICM 2012

This editorial refers to the article available at: doi:10.1007/s00134-012-2490-7.

J.-C. M. Richard (ه)

Intensive Care Department, University Hospital of Geneva, Geneva, Switzerland

e-mail: jcm.richard@hcuge.ch

J. J. Marini

Pulmonary and Critical Care,

University of Minnesota and Regions Hospital,

St. Paul, MN, USA

During the last pandemic, experience in the management of the most severely affected patients with influenza A (H1N1)-related acute respiratory distress syndrome (ARDS) included increased use of extracorporeal membrane oxygenation (ECMO) [1, 2]. Growing interest in this technique has been spurred by the results of a large cohort study in which transfer to an ECMO center was associated with lower hospital mortality than matched non-ECMO-referred patients [3]. To date, it has been difficult to establish recommendations for ECMO referral, since neither the type of patients who benefit from this technique nor the exact timing of the switch from conventional treatment to ECMO have been systematically investigated [4].

In this issue of Intensive Care Medicine, Grasso et al. [5] evaluate whether the use of transpulmonary pressure (PTP) [as opposed to airway pressure (Paw) alone] as a surrogate of the true lung distending pressure might lead to safely increased positive end-expiratory pressure (PEEP) and improved oxygenation, thereby avoiding unnecessary ECMO. In fact, whereas Paw is influenced by chest wall properties and respiratory muscle activity, the PTP (Paw - pleural pressure) enables estimation of passive lung's actual distending pressure, unencumbered by the influence of the chest wall and patient effort on recorded airway pressures. To assess PTP, an esophageal balloon catheter was used to estimate global pleural pressure, a venerable laboratory technique that has recently been deployed in the clinical setting of lung protective ventilation [6]. Grasso and colleagues hypothesized that, despite high Paw, the actual PTP observed in some very severe patients with ARDS might be low enough to allow safe increases of PEEP and improved lung recruitment when a relatively large proportion of Paw dissipates against a stiff chest wall. In the current study, the authors nicely demonstrated that PTP, as opposed to unadjusted Paw, effectively guided the selection of PEEP while keeping end-inspiratory PTP in a theoretically safe range. Many of the studied patients had abnormal chest wall elastance related to obesity. Because the chest wall may account for an unexpectedly high fraction of total respiratory system elastance even in lung injured patients, relying on Paw to estimate distension and guide recruitment may be misleading [7]. Using PTP to optimize PEEP and tidal volume (Vt) is a particularly attractive option for influenza A (H1N1) patients with diffuse ARDS which appears to have occurred disproportionately often in the obese.

Clinical findings have supported the idea that endexpiratory collapse, inspiratory recruitment, and potential regional overdistension are continuous and interdependent phenomena [8]. Nevertheless, the complex relationship between PTP, recruitment, and the risk of overdistension has frustrated most attempts to establish reliable rules with which to govern clinical choices among options for selecting PEEP and Vt [9]. 
Findings reported in this current case series may be viewed as a partial "proof of concept," but several methodological limitations relating to the design and the reliability of esophageal pressure (Pes) measurement may limit broader clinical application of this approach to everyday practice.

First, the authors postulated that $27 \mathrm{cmH}_{2} \mathrm{O}$ could rationally be considered the safe upper limit target for PTP. Clinical observations supporting this statement are relatively scarce. In a large group of patients with and without ARDS, Chuimello et al. investigated the relationship between stress (i.e., transpulmonary pressure) and strain defined as the ratio between $\mathrm{Vt}$ and end-expiratory lung volume [10]. With imaging data used as the criterion, the authors demonstrated that plateau pressure (Pplat) and Vt are imprecise surrogates for lung tissue stress and strain. The poor relationship they observed between Pplat and lung distension was related to the heterogeneous influence of the chest wall. Interestingly, the stress to strain ratio (i.e., specific elastance) was remarkably constant (around $13 \mathrm{cmH}_{2} \mathrm{O}$ ) whatever the disease severity and combination of PEEP and Vt. Based on animal studies $[11,12]$ which suggest that tidal ventilation at strain ratio above 2 (which corresponds to an end-inspiratory lung volume approaching total lung capacity) may prove rapidly lethal, the authors proposed to set the harmful threshold arbitrarily at $27 \mathrm{cmH}_{2} \mathrm{O}$ $\left(2 \times 13.5 \mathrm{cmH}_{2} \mathrm{O}\right)$. While this proposal would appear conceptually sound, the designated criterion value for PTP is based on animal observations rather than clinical studies. Moreover, in a clinical study investigating the chest wall's contribution to the inspiratory pressure-volume relationship of the respiratory system during ARDS, Owens et al. [13] observed relatively little influence. This may have been due to the fact that most of these patients suffered from ARDS related to medical illnesses. However, in patient with ARDS related to intra-abdominal disease and in those exhibiting high BMI, the chest wall may account for a much higher proportion of total elastance $[14,15]$. In accordance with those observations, Grasso et al. [5] suggested that targeting Pplat of $30 \mathrm{cmH}_{2} \mathrm{O}$ may be excessively prudent in some patients and may lead to unjustified recommendations for ECMO management. On the other hand, Terragni et al. [16] showed in 30 patients managed according to the ARDS network strategy that one-third experienced tidal hyperinflation [assessed by CT scan systematic analysis] despite a Vt of $6 \mathrm{ml} / \mathrm{kg}$ PBW and a Pplat limited at $30 \mathrm{cmH}_{2} \mathrm{O}$. In that study, patients exhibiting Pplat below $28 \mathrm{cmH}_{2} \mathrm{O}$ were significantly less prone to hyperinflation. How to reconcile these contrasting observations suggesting that a $30 \mathrm{cmH}_{2} \mathrm{O}$ Pplat may both overestimate distension and underestimate the true hyperinflation is challenging without invoking important differences in lung disease severity and/or chest wall distensibility. Predicting mechanical properties from traditional observations of physical examination or airway pressure measurements is difficult in clinical practice, especially when disease is unevenly distributed and spontaneous breathing efforts are permitted or encouraged. In this context, Pes measurement and transpulmonary pressure estimation may be essential in differentiating patients who may benefit from a PEEP increase because of increased chest wall elastance from those at risk of hyperdistension despite relatively low Paw. Yet, the true tension experienced in the alveolar micro-environment may only be crudely represented by the PTP, however accurate the latter might be measured.

The second point that merits discussion concerns the potential impact of higher PEEP levels on hemodynamics. The physiological rationale of the study reported by Grasso et al. relied on the fact that ECMO is a rescue therapy that should be avoided whenever possible. Supposing that this statement is correct, the consequence of avoiding ECMO according to their strategy (considered safe as regards to end-inspiratory PTP) will be a potentially major increase of PEEP. Therefore, one price to pay that should be considered in avoiding ECMO's drawbacks is the possible impact of greater lung distension and higher pleural pressure on hemodynamic status. The same group of authors have shown several years ago that recruitment maneuvers were significantly less efficient (and potentially harmful) in patient exhibiting high chest wall elastance compared with ARDS in which the chest wall was not altered [17]. Predictably, the authors observed in this study a significantly larger impact of Paw on cardiac output in the group of patients with higher chest wall elastance. This harmful hemodynamic effect (which in addition did not result in oxygenation improvement) expected in patients with high chest wall elastance should be considered as a possible price to pay for a strategy based on PTP measurement to increase PEEP in order to avoid ECMO requirement.

Finally, before we can embrace Pes as an accurate surrogate for the pressure that surrounds the lung, we must understand that the esophageal balloon catheter measures the least pressure in its local environment, and that this pressure may vary considerably from that existing elsewhere. Even locally, the sensitivity of Pes to changes in abdominal pressure and lung volume is suspect at end exhalation [18].

Despite numerous shortcomings, the option to sense pleural pressure at the bedside by an esophageal balloon represents the next logical step in a more physiological and individually tailored approach to lung protective ventilation. 


\section{References}

1. Davies A, Jones D, Bailey M, Beca J, Bellomo R, Blackwell N, Forrest P, Gattas D, Granger E, Herkes R, Jackson A, McGuinness S, Nair P, Pellegrino V, Pettila V, Plunkett B, Pye R, Torzillo P, Webb S, Wilson M, Ziegenfuss M (2009) Extracorporeal membrane oxygenation for 2009 influenza $\mathrm{A}(\mathrm{H} 1 \mathrm{~N} 1)$ acute respiratory distress syndrome. JAMA 302:1888-1895

2. Fuhrman C, Bonmarin I, Bitar D, Cardoso T, Duport N, Herida M, Isnard $\mathrm{H}$, Guidet B, Mimoz O, Richard JC, Brun-Buisson C, Brochard L, Mailles A, Paty AC, Saura C, Levy-Bruhl D (2011) Adult intensive-care patients with 2009 pandemic influenza A(H1N1) infection. Epidemiol Infect 139:1202-1209

3. Noah MA, Peek GJ, Finney SJ, Griffiths MJ, Harrison DA, Grieve R, Sadique MZ, Sekhon JS, McAuley DF, Firmin RK, Harvey C, Cordingley JJ, Price S, Vuylsteke A, Jenkins DP, Noble DW, Bloomfield R, Walsh TS, Perkins GD, Menon D, Taylor BL, Rowan KM (2011) Referral to an extracorporeal membrane oxygenation center and mortality among patients with severe 2009 influenza A (H1N1). JAMA 306:1659-1668

4. Checkley W (2011) Extracorporeal membrane oxygenation as a first-line treatment strategy for ARDS: is the evidence sufficiently strong? JAMA 306:1703-1704

5. Grasso Salvatore, Terragni Pierpaolo, Birocco Alberto, Urbino Rosario, Del Sorbo Lorenzo, Filippini Claudia, Mascia Luciana, Pesenti Antonio, Zangrillo Alberto, Gattinoni Luciano, Marco Ranieri V (2012) ECMO criteria for influenza A (H1N1)-associated ARDS: role of transpulmonary pressure. Intensive Care Med. doi: 10.1007/s00134-012-2490-7
6. Talmor D, Sarge T, Malhotra A, O’Donnell CR, Ritz R, Lisbon A, Novack V, Loring SH (2008) Mechanical ventilation guided by esophageal pressure in acute lung injury. N Engl J Med 359:2095-2104

7. Gattinoni L, Pelosi P, Suter PM, Pedoto A, Vercesi P, Lissoni A (1998) Acute respiratory distress syndrome caused by pulmonary and extrapulmonary disease. Different syndromes? Am J Respir Crit Care Med 158:3-11

8. Jonson B, Richard JC, Straus C, Mancebo J, Lemaire F, Brochard L (1999) Pressure-volume curves and compliance in acute lung injury: evidence of recruitment above the lower inflection point. Am J Respir Crit Care Med 159:1172-1178

9. Pelosi P, Goldner M, McKibben A, Adams A, Eccher G, Caironi P, Losappio S, Gattinoni L, Marini JJ (2001) Recruitment and derecruitment during acute respiratory failure: an experimental study. Am J Respir Crit Care Med 164:122-130

10. Chiumello D, Carlesso E, Cadringher P, Caironi P, Valenza F, Polli F, Tallarini F, Cozzi P, Cressoni M, Colombo A, Marini JJ, Gattinoni L (2008) Lung stress and strain during mechanical ventilation for acute respiratory distress syndrome. Am J Respir Crit Care Med 178:346-355

11. Mandava S, Kolobow T, Vitale G, Foti G, Aprigliano M, Jones M, Muller E (2003) Lethal systemic capillary leak syndrome associated with severe ventilator-induced lung injury: an experimental study. Crit Care Med 31:885-892

12. Kolobow T, Moretti MP, Fumagalli R, Mascheroni D, Prato P, Chen V, Joris M (1987) Severe impairment in lung function induced by high peak airway pressure during mechanical ventilation. An experimental study. Am Rev Respir Dis 135:312-315
13. Owens RL, Hess DR, Malhotra A, Venegas JG, Harris RS (2008) Effect of the chest wall on pressure-volume curve analysis of acute respiratory distress syndrome lungs. Crit Care Med 36:2980-2985

14. Ranieri VM, Brienza N, Santostasi S, Puntillo F, Mascia L, Vitale N, Giuliani R, Memeo V, Bruno F, Fiore T, Brienza A, Slutsky AS (1997) Impairment of lung and chest wall mechanics in patients with acute respiratory distress syndrome: role of abdominal distension. Am J Respir Crit Care Med 156:1082-1091

15. Gattinoni L, Chiumello D, Carlesso E, Valenza F (2004) Bench-to-bedside review: chest wall elastance in acute lung injury/acute respiratory distress syndrome patients. Crit Care 8:350-355

16. Terragni PP, Rosboch G, Tealdi A, Corno E, Menaldo E, Davini O, Gandini G, Herrmann P, Mascia L, Quintel M, Slutsky AS, Gattinoni L, Ranieri VM (2007) Tidal hyperinflation during low tidal volume ventilation in acute respiratory distress syndrome. Am J Respir Crit Care Med 175:160-166

17. Grasso S, Mascia L, Del Turco M, Malacarne P, Giunta F, Brochard L, Slutsky AS, Marco Ranieri V (2002) Effects of recruiting maneuvers in patients with acute respiratory distress syndrome ventilated with protective ventilatory strategy. Anesthesiology 96:795-802

18. Valenza F, Chevallard G, Porro GA, Gattinoni L (2007) Static and dynamic components of esophageal and central venous pressure during intra-abdominal hypertension. Crit Care Med 35:1575-1581 